\title{
The Scientist as an Advocate: When and When Not
}

\author{
Michael J. Wade ${ }^{1 *}$, Urs Broderick Furrer ${ }^{2}$ \\ ${ }^{1}$ Wade Research, Inc., Marshfield, MA, USA \\ ${ }^{2}$ Harriton and Furrer, LLP, Armonk, NY, USA \\ Email: ^mjwade@waderesearch.com, UBFurrer@hflawllp.com
}

How to cite this paper: Wade, M.J. and Furrer, U.B. (2018) The Scientist as an Advocate: When and When Not. Journal of Environmental Protection, 9, 501-507. https://doi.org/10.4236/jep.2018.95030

Received: March 16, 2018

Accepted: May 11, 2018

Published: May 14, 2018

Copyright (c) 2018 by authors and Scientific Research Publishing Inc. This work is licensed under the Creative Commons Attribution International License (CC BY 4.0).

http://creativecommons.org/licenses/by/4.0/

\begin{abstract}
As most of us fundamentally know, there are times a scientist should and should not act as an advocate. As an individual, advocating for environmental preservation is almost required as a member of the world's scholarly scientific community. However, when that same scientist is asked to offer opinion testimony as an expert witness within the parameters of a lawsuit filed within their particular legal system, there is no room for advocacy. Because it appears that the line an expert scientist must not cross is becoming ever more blurred, we intend to discuss when a scientist should and should not act as an advocate and the reasons that the line between advocate and impartial expert exists. In a legal setting such as a trial or an arbitration hearing, scientists are required to be qualified as an "expert" on the technical subject being considered by the trier of fact before rendering any opinions. Indeed, scientists, unlike all other witnesses, are permitted to present opinions regarding otherwise admissible evidence after being accepted by the Judge as a qualified expert in the field to which he or she intends to testify. However, while the scientist is permitted to present his or her opinions, the scientist is not permitted to advocate for a position or for their interpretation of the evidence presented in a courtroom trial or an arbitration hearing. Rather, those roles are reserved for the parties' attorneys. Rather, it is the role of the scientist to solely offer opinions with respect to the evidence or facts which are the subject of the dispute. In doing so, the scientist is expected to act as disinterested scholar or teacher faithfully interpreting the data whatever it may reveal. In the eyes of established legal systems, such as the United States (U.S.) or United Kingdom (U.K.), were a scientist to attempt to become an advocate, rather than a scholar and teacher, that scientist's opinions would no longer be based on fact but, rather, the interests of his or her client, thus damaging the scientist's credibility. In doing so, the expert could potentially cause irreparable harm to his or her client's case and his or her reputation.
\end{abstract}




\section{Keywords}

Expert Witness, Environmental Forensics, Advocate, False Advocacy

\section{Introduction}

In the emerging field of environmental forensics, the scholar/scientist is a necessary player in the legal system's attempt to reach a just resolution of disputed claims. In so doing, the scholars and scientists are not isolated in this process. Rather, they are thrust to the forefront of the resolving the legal issues involved. Indeed, the complexities inherent in environmental forensics necessitate the legal system's reliance on scholars/scientists.

Making the transition from the role of scientist to the role of testifying expert can be difficult. A scientist is the product of their scholarly educational experiences, personal experiences, and maturation as their scientific career progresses. Put another way, they are the product of their beginnings, their successes and failures along the way as well as their aspirations for the future. The inclination to advocate for one's beliefs as a scientist conflicts with the requirements of our legal system in which the trier of fact's role is to discern the truth of the issues presented.

Within the legal systems, the requirements of the different roles of scientist, testifying expert and legal advocate have evolved as legal systems themselves have evolved throughout the years.

\section{The Need for Impartial Experts}

In the United States, at the outset of the process, the parties to a dispute rely on trained lawyers to navigate the maze of the legal system, evaluate the merits of their client's claims and defenses and advise them on the applicable laws and how those laws impact those claims and defenses. In complicated environmental matters, parties and lawyers must turn to trained scholars/scientists to understand the scientific concepts and data and the implications to their case and to assist them in explaining those scientific concepts and the meaning of the data to judges and juries.

Upon retention, the scholar/scientist must work with the party or parties that hired him or her to understand the issues presented and how and to whom they are going to be presented. A jury? A judge? A regulatory tribunal? An arbitrator? The scientist must then formulate working hypotheses, collect information and/or environmental data, including, perhaps, test samples after which he or she must review the empirical data, evaluate the working hypotheses and formulate conclusions based not on the interests of his or her client that retained him or her but, rather, solely on the data, facts and evidence. All these efforts, collectively referred to as the Scientific Process, much be focused on answering the questions presented from a scholar/scientist's point of view rather than that 
of an advocate. This is fundamental for two primary reasons.

First, from a lawyer's point of view, if a retained scholar/scientist is impartially evaluating the evidence, the lawyer may discern the validity of his or her client's position and whether the client's position is supported by the evidence. This is impossible where the scholar/scientist attempts to act as an advocate reaching conclusions not based on the facts but, rather, based on who is retaining him or her. Indeed, an attorney cannot properly advise the client as to the merits of their case (and whether a case should be settled or tried) when the lawyer does not know if the facts are truly supportive or detrimental to the client's case. That the field of environmental forensics is far more complex than most types of scientific evidence utilized in trials or hearings makes it all the more important that the lawyer fully understand the relevant scientific concepts, the data and the implications of both to the client's case.

Second, in the American legal system, like the U.K. legal system, the fundamental reason for expert testimony is the explanation of technical issues to the trier of fact. Simply stated, the trier of fact must be able to rely on the expert's opinion testimony as fair and impartial. Indeed, the trier of fact in the U.S. and U.K. is tasked with determining which party or parties are responsible for the environmental contamination in issue. In order to perform the task for which it is tasked, the trier of fact must not only understand the relevant scientific issues, but must be able to rely on opinions from the parties' respective experts which are based on the experts' impartial evaluation and explanation of the evidence.

Indeed, under a scenario where experts were permitted to testify as advocates, triers of fact would be unable to reach just decisions based on the evidence as the expert testimony would be no different than the testimony, often self-serving, of the parties themselves. Were experts permitted to testify as advocates, there would be no assurance that the triers of fact would be able to truly understand the scientific concepts and evidence. Rather, they would end up basing their decisions on skewed explanations of scientific concepts and biased interpretations of data neither of which would assist the trier of fact in reaching a just and fair determination.

\section{Discussion}

The scholarly road traveled in gaining a successful advanced scientific educational position can be long and, at times, difficult. The foundation for such a position is put in place in the earliest of educational experiences and goes with the natural inclinations of the individual. Not everyone seeks nor wants such experiences. For those that do, almost no one travels that road alone. Almost every established scientist can attribute their successes to selected few individuals in the secondary, college and post-graduate educational institutions. Thus, in a very real sense, each newly degreed scientist is the product of previous scholars, professors who experienced the same progressions from yet earlier professors or mentors in the educational progression. In our view, paying respect to individuals 
who pass their previous educational experiences on to the new generation engenders an obligation to honor such individuals in the generations of work to follow.

Society, too, is investing in the success of the individual by establishing and supporting educational institutions. By allocating resources to the process, society is making a commitment to its output, its professors, students and ultimately its graduating scholars. Clearly, society does so because of the resulting benefits including advanced technologies, a better understanding of the world around us, and life-saving or life-prolonging medical breakthroughs. And, in a different but very real sense, families invest in the success of children by supporting educational endeavors. The effort can be somewhat different. While the student is working diligently in school, the family is working to support and maintain the family unit which still includes the student scholar. There is a very real cost to both investments. So, too, there is a very real obligation that the successful scientist must honor both family and their overall society.

Most significantly, however, is the obligation to science itself. A scientist is obligated to share the work, the outcome, the effort; whether it is shared through associations made within professional societies, giving talks at national or international meetings, publication of articles in peer reviewed technical journals, writing textbooks, or simply through day-to-day discussions among fellow scientists. Simply stated, a scientists' efforts must be shared. Within all of these avenues it is perfectly appropriate for scientist to promote their scholarly work or the work of others.

Taken together, therefore, a scholar broadly speaks for science, the professionals who brought them forward in their disciplines, and for their families and society itself. It is this combination of influences that every scientist is duty bound to honor. For example, it is perfectly appropriate for a scientist to speak out publically on an issue which directly involves their scientific endeavors. In fact, considering all of the obligations, not speaking out on such issues is tantamount to denying one's scholarly upbringing or educational heritage.

Holding scholars out to the broader society for key roles is not a new concept. Early in the seventh century CE, Chinese Emperor Yang of the Sui dynasty built into the examination selection system of "classicists" and that of "cultivated talents" the role of "presented scholars." Promotion of "experts" and examination were unified in one system [1] [2]. More recent examples of this process of holding scholars out for key roles in society can be found in the U.S. when, in his 1956 Harvard University commencement speech, future American president John F. Kennedy advocated the involvement of scholars in the formation of public policy, saying [3] " $\ldots$ the political profession needs both the technical judgment and the disinterested viewpoint of the scholar." The key words in these two instances are "experts" and "disinterested." Scholarship and political processes need such disinterested experts. The legal system demands it.

Furthermore, given the hardening of political viewpoints today, especially as it pertains to scholarly work such as research on global warming or climate 
change, and international treaties that attempt to deal with such issues, such words offer a warning to us that is only now being rediscovered. Scientists have a moral obligation to speak out on such issues. Such is especially true in the field of environmental forensic sciences. However, the scientific advocacy that is required of today's scholar in areas where their scientific expertise is focused must be curbed within the legal setting from the point of initial expert retention to the conclusion of the legal process.

It is our opinion that advocacy in the legal system must be left to the lawyers. First and foremost, lawyers are trained to be advocates while scholars/scientists are trained to be disinterested and impartial. As experts, scientists must impartially review and interpret the facts and explain the concepts in issue. As previously discussed, it not the role of the expert to try to "win the case" by force of personality or skewing the interpretation of the data. Experts are hired to convey knowledge in her field of expertise that allows for fact-finding; rather than, being a part of the legal team and becoming an advocate in the court-room [4]. It is left to the attorneys to provide counsel and advocacy for their clients. Within the U.S. legal system for example, at the outset of the process, the parties to a dispute rely on trained lawyers to determine case strategy, evaluate the merits of their claims and defenses and advise them on the applicable laws and how those laws impact those claims and defenses.

Judge Strine highlighted in an opinion and voiced his concerns that parties experts' were advocating for their client in the court-room rather than assisting the trier of fact, saying "These starkly contrasting presentations have, given the duties required of this court, imposed upon trial judges the responsibility to forge a responsible valuation from what is often ridiculously biased "expert" input" [5]. The trier of fact should not have to weed through an expert's reports or testimony in order to determine what are scientifically founded opinions versus the expert's advocacy added to sway the judge or jury. Rather, once again, advocacy must be left to the lawyers.

Unfortunately, in the field of environmental forensics, we have seen more and more scientists trying to please their clients by acting as advocates rather than impartial scholars interpreting the evidence in an apparent hope that by winning cases, they or their companies will also win more business and, hence, personally prosper [6]. Such behavior has no role in a legal system where truth is the ultimate goal.

In the United States, the basis for allowing scientific opinions to be introduced in court, as opposed to a simple presentation of uncontroverted facts (i.e., lab results and the interpretation of those results), is that a trier of fact's understanding of a given technical issue can be facilitated by the testimony of a professional witness whose opinions are based on: 1) generally accepted, testable theories; 2) using valid and reliable procedures with positive results; 3) which have been documented in the peer-reviewed literature; and 4) widely accepted within the broad scientific community [7] [8]. In a very real sense, the scientist becomes the teacher of the judge and jury in a court or arbitration proceeding. 
Moreover, in the United States legal system, like the United Kingdom legal system, the fundamental reason for expert testimony is the explanation of technical issues to the trier of fact [9]. In order to properly do their job, the trier of fact must not only understand the relevant scientific issues, the trier of fact must be able to rely on opinions from the parties' respective experts, based on the impartial evaluation and explanation of the evidence, in order to reach the proper conclusion.

At the same time, it is the parties' respective lawyers who are recognized as the advocates for their client's theory of the case. Indeed, the United States Model Rule of Professional Conduct specifically provides that as an "advocate, a lawyer zealously asserts the client's position under the rules of the adversary system" [10]. Of course, a lawyer cannot advocate a client's position without a full understanding of that position including both the facts that support it and those that do not. Indeed, in such a technically challenging field as environmental forensics, an attorney cannot properly ascertain the strengths and weaknesses of a client's case if he or she cannot be sure that the retained expert is giving him or her impartial scientific advice rather than simply what the expert believes his client wants to hear (e.g. "it's not your contamination").

In the United Kingdom, the rules are clear on this issue: its Civil Procedural Rules 35.3 provides that it is the duty of experts to help the court on matters within their expertise, and that this duty overrides any obligation to the person from whom experts have received instructions or by whom they are paid [11]. The United States does not have a rule that explicitly addresses this issue; however, it is an implied duty of all experts in the United States. Moreover, if there is one overriding implied assumption that every litigator should make, it is that his adversary will be prepared and will be ready to challenge every opinion of his client's expert. If the expert's opinions are not scientifically valid and are not consistent with the evidence, the opposing party will surely demonstrate that to the trier of fact resulting not only in a judicial finding against the client but great embarrassment to the attorney and retained expert. It is imperative that an expert witness must approach every question with independence and objectivity [12].

\section{Conclusions}

In sum, in complicated environmental matters involving forensic science, the role of the scholar/scientist is critical and he or she must base their conclusions solely on the available scientific facts presented. Indeed, there is a fundamental incompatibility of open and fair legal systems where triers of fact attempt to reach fair and just conclusions based upon the evidence and a system where expert scientists strive for personal achievement or enrichment by trying to "win the case" and seek to advocate their client's position through "false advocacy." Such a misguided approach to forensic environmental science will, if left unchallenged, tar all scholars/scientists as little more than "guns for hire," returning, in a sense, the resolution of disputes to the non-legal methods our ancestors used before the development of our current legal systems. Today as the forensic 
environmental sciences are expanding into a more broad based investigatory approach, it has never been more important to present the fact-based truth, not what someone wants the truth to be.

In conclusion, we believe that there is a fundamental incompatibility of our open legal system where on one hand, triers of fact attempt to reach fact based truth and on the other hand, expert scientists strive for personal achievement or enrichment by trying to "win the case" through "false advocacy," seeking to advocate their client's position regardless of what the assembled data show.

\section{Acknowledgements}

The essence of this paper was presented jointly by both authors as a single keynote talk at the Plenary Session of the 2017 Annual Conference of the International Network of Environmental Forensics (INEF), held in Beijing China in July 2017. INEF 2017 Beijing was sponsored jointly by INEF, the Royal Society of Chemistry, the Chinese Society for Environmental Sciences and the University of Chinese Academy of Sciences. The authors wish to thank the convener Dr. Jun $\mathrm{Lu}$ for his dedication to the issues discussed. We also wish to thank Ms. Sarah J. Cafran, Esq. for additional legal research.

\section{References}

[1] Ru, L., Zhu, R.X., Yao, D.L., Yang, Z.X. and Wang, D.C. (1992) “Kejuzhi,” in Zhongguo da baikequanshu, Zhongguolishi. Vol. 1, Zhongguo da baikequanshuchubanshe, Beijing/Shanghai, 527.

[2] Xu, C.S. (1992) "Kejuzhidu", in Zhongguo da baikequanshu, Jiaoyu. Zhongguo da baikequanshuchubanshe, Beijing/Shanghai, 202.

[3] Kennedy, J.F. (1956) Harvard University Commencement Speech. Harvard University Archives.

[4] Sanders, J. (2007) Expert Witness Ethics. Fordham Law Review, 76, 1539.

[5] Finkelstein v. Liberty Digital, Inc. No. CIV.A. 19598, 2005 WL 1074364, at *13 (Del. Ch. Apr. 25, 2005).

[6] Huyghe Sr., S. and Chan, A. (2013) The Evolution of Expert Witness Law under UK and US Jurisdictions. Construction Law International, 8, 14.

[7] Daubert v. Merrell Dow Pharm., Inc., 509 U.S. 579, 113 S. Ct. 2786, 125 L. Ed. 2d 469 (1993).

[8] Kumho Tire Co. v. Carmichael, 526 U.S. 137, 119 S. Ct. 1167, 143 L. Ed. 2d 238 (1999).

[9] United States Federal Rules of Evidence, Testimony by Expert Witness, Rule 702 (2011)

[10] Model Rules of Professional Conduct, American Bar Association, Preamble and Scope (1983)

[11] United Kingdom Civil Procedural Rules, Experts-Overriding Duty to the Court, Rule 35.3 (1984)

[12] Lubet, W. (1999) Expert Witnesses: Ethics and Professionalism. Georgetown Journal of Legal Ethics, 12, 465. 